\title{
Effects of dexamethasone, ascorbic acid and $\beta$-glycerophosphate on the osteogenic differentiation of stem cells in vitro
}

Fabian Langenbach ${ }^{*}$ and Jörg Handschel

\begin{abstract}
The standard procedure for the osteogenic differentiation of multipotent stem cells is treatment of a confluent monolayer with a cocktail of dexamethasone (Dex), ascorbic acid (Asc) and $\beta$-glycerophosphate ( $\beta$-Gly). This review describes the effects of these substances on intracellular signaling cascades that lead to osteogenic differentiation of bone marrow stroma-derived stem cells. We conclude that Dex induces Runx2 expression by FHL2/ $\beta$-catenin-mediated transcriptional activation and that Dex enhances Runx2 activity by upregulation of TAZ and MKP1. Asc leads to the increased secretion of collagen type I (Col1), which in turn leads to increased Col1 $1 / \alpha_{2} \beta_{1}$ integrin-mediated intracellular signaling. The phosphate from $\beta$-Gly serves as a source for the phosphate in hydroxylapatite and in addition influences intracellular signaling molecules. In this context we give special attention to the differences between dystrophic and bone-specific mineralization.
\end{abstract}

\section{Introduction}

Osteogenic differentiation protocols using dexamethasone (Dex), ascorbic acid (Asc) and $\beta$-glycerophosphate $(\beta-G l y)$ are frequently used for many experimental approaches, including tissue engineering approaches or simply the approval of differentiation capabilities of particular cell types. Stem cells from several tissues are promising candidates for such approaches. However, only a few cell types are able to form heterotopic bone while many cell types are able to form mineralized tissue. Many studies report that skeletal stem cells (SSCs) from bone marrow and unrestricted somatic stem cells

\footnotetext{
* Correspondence: fabian.langenbach@med.uni-duesseldorf.de Cranio and Maxillofacial Surgery, Heinrich-Heine University, Moorenstr. 5, 40225, Düsseldorf, Germany
}

from umbilical cord blood are able to establish a hematopoietic microenvironment and to form bone after implantation [1-4]. For general information on the delicate differences between stem cells and the uncertainties about the definition of mesenchymal stem cells, please refer to the commentary of Bianco and colleagues [5]. Furthermore, we recommend the review of Robey on cell sources for bone regeneration, which highlights the importance of SSCs in osteogenic tissue engineering [1]. In this context, it is important to note that the prolonged culture of bone marrow stromal cells (BMSCs) can deplete the SSC pool or lead to over-dilution of SSCs in the heterogeneous BMSC population $[1,6]$.

In this review, we describe the latest findings concerning the underlying mechanisms involved in osteogenic differentiation of BMSC cultures under the influence of Dex, Asc and $\beta$-Gly (the combination is frequently called DAG). Furthermore, special focus is put on the difference between bone-specific and dystrophic mineralization processes under the influence of this combination.

\section{Dexamethasone}

At least a 3-week period of continuous treatment of a confluent monolayer of cells with Dex, in combination with $\beta$-Gly and Asc, is required for osteogenic differentiation [7], demonstrating that the differentiation process does not start with an initial event that is sufficient by itself to induce final in vitro mineralization, but that Dex, Asc and $\beta$-Gly orchestrate several regulatory mechanisms over a period of time. Several approaches have been undertaken in order to elucidate the function of Dex, which have often resulted in conflicting findings due to differences in the differentiation state and the osteogenic potential of the cells.

Since Tenenbaum and Heersche [8] demonstrated in 1985 that the optimal concentration of Dex for osteogenesis of chick periosteum cells was $100 \mathrm{nM}$, this 
concentration has been used in many approaches for the differentiation of cells. In a study by Walsh and colleagues [9], in vitro analysis of BMSCs from 30 human donors has provided evidence that a level of Dex that is similar to the physiological level of glucocorticoids (10 $\mathrm{nM}$ ) is the optimal concentration for mineralized nodule formation. A review by Seong and colleagues [10] noted that both concentrations have been used at similar frequencies in research articles. Recently, Alm and colleagues [11] found that transient $100 \mathrm{nM}$ Dex treatment for 1 week reduces inter- and intra-individual variations in osteoblastic differentiation of BMSCs. Furthermore, it was reported that Dex prevents apoptosis of BMSCs in confluent cultures [12] and promotes mesenchymal stem cell proliferation [13].

\section{Dexamethasone induces Runx2 expression by FHL2/ $\beta$-catenin-mediated transcriptional activation}

The precise mechanisms of how Dex induces osteogenesis in vitro remained unclear until Hamidouche and colleagues [14] demonstrated that a LIM-domain protein with 4.5 LIM domains (FHL2) mediates Dex-induced mesenchymal cell differentiation into osteoblasts by activating $\mathrm{WNT} / \beta$-catenin signaling-dependent Run $x 2$ expression. They demonstrated that FHL2 is upregulated in response to Dex, presumably due to binding to a glucocorticoid response element in the promoter of FHL2. In the presence of Wnt3a, an activator of the canonical WNT signaling pathway, binding of FHL2 to $\beta$ catenin potentiates the transport of $\beta$-catenin to the nucleus, where it binds TCF/LEF-1 and leads to the transcription of Runx2. Evidence for direct interaction of FHL2 and $\beta$-catenin was provided by detection of coimmunoprecipitation. Previously, other groups demonstrated that canonical Wnt signaling promotes osteoblast differentiation, in part through Runx2 expression [15]. Besides Runx2 upregulation after FHL2 overexpression, collagen type I (Col1) is also upregulated [14]. This was demonstrated using a Runx2 defect mutant, which had no influence on Col1 expression, leading to the suggestion that Col1 also depends on FHL2/ $\beta$-catenindependent transcriptional activation.

\section{Dexamethasone regulates Runx2 via activation of TAZ}

Besides being responsible for regulating the expression of Runx2 by the above-mentioned FHL2-mediated transcriptional activation, recent findings have elucidated Dex regulation of Runx2 function via the activity of the $\beta$-catenin-like molecule TAZ (transcriptional coactivator with PDZ-binding motif) [16] (Figure 1). TAZ contains a coiled-coil carboxy-terminal domain that recruits core components of the transcriptional machinery and a specific domain that binds to the Pro-Pro-X-Tyr motif (where $\mathrm{X}$ is any amino acid) of Runx2 $[17,18]$.
Interestingly, in rat and murine BMSCs, TAZ coactivates Runx2-dependent gene transcription while repressing peroxisome-proliferator-activated receptor- $\gamma$ dependent gene transcription, a critical transcription factor for adipogenic differentiation [16,18]. Hong and colleagues [16] demonstrated that the expression of TAZ is increased in response to Dex in rat BMSCs and suggested that TAZ is involved in the signaling pathway of Dex. Zebrafish that were TAZ-depleted did not form bone, providing further evidence for the importance of TAZ in osteoblast differentiation [18]. It seems that TAZ is a crucial factor in the lineage decision of stem cells of the BMSC population.

\section{Dexamethasone regulates Runx2 via activation of MKP-1}

Another mechanism by which Dex further induces osteogenesis is the modulation of Runx2 phosphorylation via the mitogen-activated protein kinase (MAPK) phosphatase (MKP-1) (Figure 1). In fact, Phillips and colleagues [19] demonstrated that Dex increases MKP-1 expression. They transfected rat dermal fibroblasts with Runx 2 and found that only in combination with Dex was the expression of osteocalcin and bone sialo protein (BSP) induced, and mineral was deposited. They also ensured that this effect was not an artifact of the nonosteogenic cells but can be also observed in primary BMSCs. It was found that the upregulation of MKP-1 results in the de-phosphorylation of serine 125 of Runx2 leading to enhanced Runx2 trans-activation. This process is crucial in osteogenic differentiation and latestage mineralization processes. Mikami and colleagues [20] found that both the timing of Dex administration and the concentration have significant effects on mineralization and differentiation. The osteogenic response to Dex may, at least in part, require the presence of Runx2, which is probably the reason for the contradictory results concerning the function of Dex in vitro. Whether MKP-1-dependent dephosphorylation is required for TAZ binding or whether these factors act together in any other way has to be verified by further experiments.

\section{Phosphorylation states regulate Runx2 activity}

Interestingly, it seems that both dephosphorylation of serine 125 of Runx 2 and phosphorylation of other serines of Runx2 lead to increased activity and gene expression of osteogenic genes in rat BMSCs $[19,21]$. In the case of Dex, however, only dephosphorylation of Runx2 has positive effects on osteogenic gene expression. By contrast, previous findings have demonstrated that several factors and events, such as contact with Coll or extracellular inorganic phosphate, lead to Runx2 activation by phosphorylation. This divergence is explained by different phosphorylation of different serine residues, 


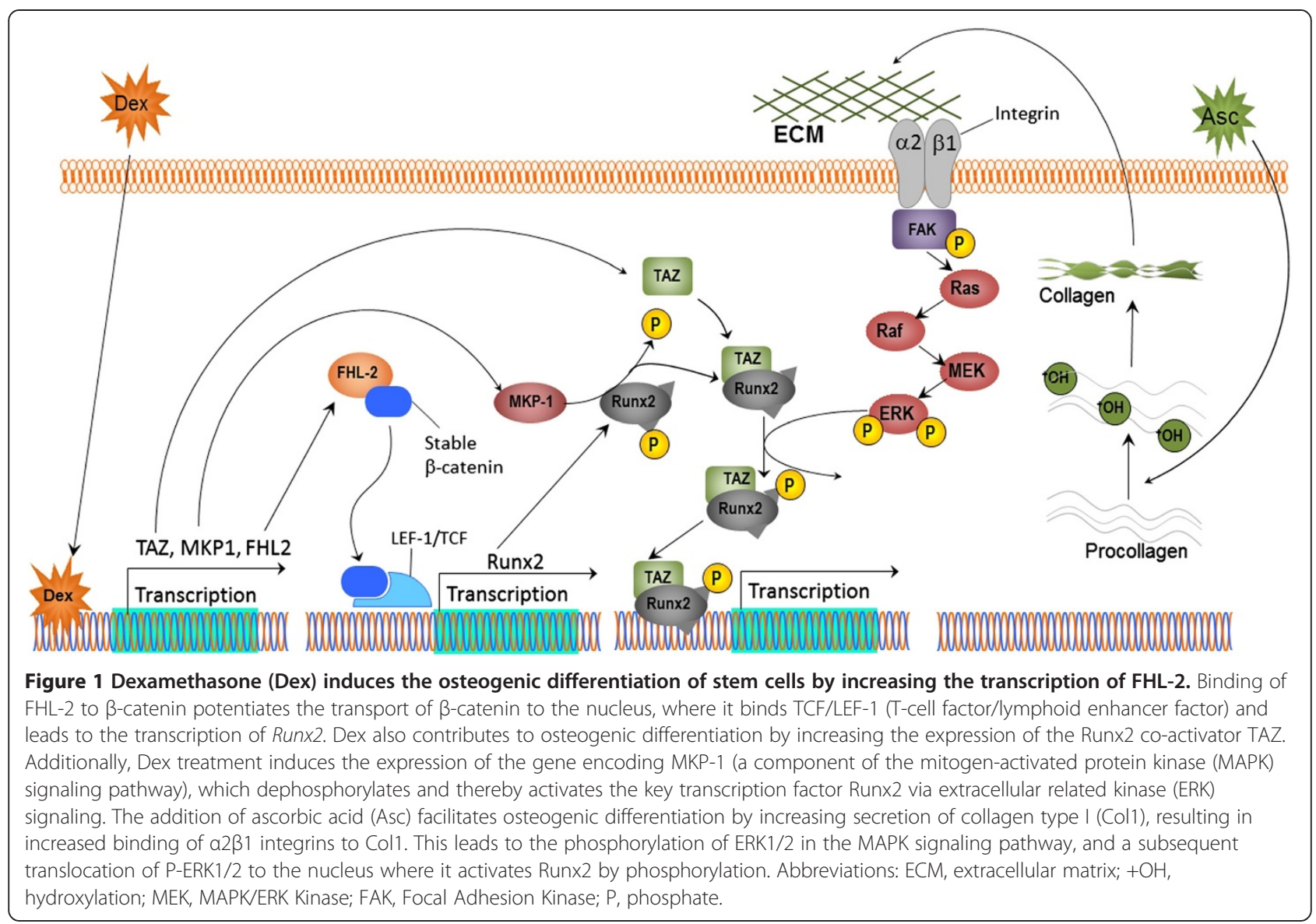

specifically the stimulatory phosphorylation of the carboxy-terminal proline-serine-threonine-rich domain of Runx2 and the stimulatory dephosphorylation of serine 125 of the amino-terminal runt domain $[19,22]$. In addition to the multiple phosphorylation sites, cell type-, species- and isoform-specific differences in Runx2 expression may account for differences in the responsiveness of Runx2 to Dex and other stimuli.

\section{Runx2-bone morphogenetic protein interaction is important for osteogenic differentiation}

A further mechanism that regulates Runx2 activity is bone morphogenetic protein (BMP) signaling, which has been shown to be required for Runx2-dependent induction of the osteoblast phenotype. Phimphilai and colleagues [23] have determined that autocrine BMP production is necessary for Runx2 to be active and that BMPs and Runx2 interact. Binding of BMPs to their receptors elicits phosphorylation of Smads 1, 5 and 8 . These Smads form complexes with Smad4 and translocate into the nucleus where they regulate gene expression of the osteogenic transcription factors Runx2, osterix and the MSX/DLX homeodomain proteins [24-26], as well as transcriptional co-activators such as p300, CBP and P/CAF [27-29]. Afzal and colleagues [29] found a Smad-interacting domain in the human Runx2 gene, which overlaps with the nuclear matrix targeting signal. The Smad-Runx2 interaction is an important aspect of Runx2 activity that regulates osteogenic differentiation. BMP-mediated regulation of Runx2 involves the binding and release of the homeodomain (HD) protein DLX5 to the Runx2 protein. During osteoblast proliferation, osteocalcin gene expression is repressed by the HD protein Msx2 (MC3T3-E1 in mouse) [24] by interacting with histone deacetylases [30] or inhibiting trans-activating factors [31] and Runx2 itself [26]. At the onset of differentiation, Msx2 is released from the chromatin of the osteocalcin gene, and Dlx3 and Dlx5 are recruited together with Runx2. In this process, Dlx3 is bound to the HD binding site in the promoter region of the osteocalcin gene. Later in osteogenic differentiation that is, during matrix mineralization - Dlx3 is replaced by Dlx5. From these results, Hassan and colleagues [26] concluded 'that multiple HD proteins in osteoblasts constitute a regulatory network that mediates development of the bone phenotype through the sequential association of distinct HD proteins with promoter regulatory elements'. Further evidence for the BMP2-Runx2 
interaction is provided by the finding that inhibition of BMP signaling disrupts the ability of Runx 2 to stimulate osteoblast differentiation in mice, leading to the suggestion by Phimphilai and colleagues that autocrine BMP production is necessary for Runx2 activity in murine stem cells of the BMSC population [23].

\section{Ascorbic acid \\ Ascorbic acid facilitates osteogenic differentiation by increasing collagen type 1 secretion}

Asc is required as a cofactor for enzymes that hydroxylate proline and lysine in pro-collagen (Figure 1) [32]. In the absence of Asc, proline cannot be hydroxylated and collagen chains are not able to form a proper helical structure [33]. Therefore, the role of Asc in osteogenic differentiation is mainly attributed to the secretion of Col1 into the extracellular matrix (ECM). Jaiswal and colleagues [34] determined that the best results for osteogenic differentiation of human BMSCs are achieved with $50 \mu \mathrm{M}$ ascorbic acid-2-phosphate, a more stable analogue of Asc under standard culture conditions. Xiao and colleagues [35] proposed a model to explain the role of ECM in the induction and maintenance of osteoblast differentiation: '(1) Osteoblasts must be in contact with a collagen-containing ECM before they can differentiate. (2) Osteoblasts bind to this ECM via interactions between coll and $\alpha_{2} \beta_{1}$ integrins. (3) Integrin ligand binding activates MAPK signaling and related pathways that transduce signals to the nucleus. (4) Runx2 is phosphorylated and activated by MAPK, thereby allowing it to stimulate osteoblast differentiation by increasing transcription of osteoblast marker genes such as osteocalcin'. This was demonstrated by the absence of osteogenesis in pre-osteoblast (MC3T3-E1 mouse pre-osteoblasts) cultures treated with collagenase, as well as in cultures in which $\alpha_{2} \beta_{1}$ integrins were suppressed [36,37]. The importance of the ECM is further highlighted by the finding that the ECM proteins Coll and vitronectin are sufficient to induce osteogenic differentiation of human BMSC cultures [38], and that unrestricted somatic stem cells from human cord blood undergo osteogenic differentiation in spheroid microtissues due to contact between cells and the ECM, without the addition of Dex, Asc and $\beta$-Gly $[39,40]$. Further reasons for the spontaneous osteogenic differentiation of microtissues and their potential use in tissue engineering have been reviewed by our group [41].

\section{Cellular interaction with extracellular matrix proteins leads to enhanced Runx2 activity}

The precise mechanism of the MAPK/extracellular related kinase (ERK)-mediated activation of Runx2 remained unclear until the finding that nuclear kinases interact directly with the chromatin of target genes in murine MC3T3-E1 cells [42,43]. Specifically, ECM interaction with the above-mentioned integrins activates the MAPK pathway, leading to accumulation of P-ERK in the nucleus. Together with Runx2, P-ERK binds to osteocalcin and BSP gene promoters to induce osteoblastspecific gene expression. The proximal promoter of the osteocalcin gene has two osteoblastic cis-acting elements (OSE2a and OSE2b), which are the targets of Runx2 and are both necessary for the expression of osteocalcin $[42,44]$. Immunofluorescence laser confocal microscopy and chromatin immunoprecipitation analyses have revealed that P-ERK, together with Runx2, selectively bind to these regions. A comparable mechanism was found for the regulation of BSP expression [42].

However, regardless of peak Runx 2 protein levels and DNA binding activity at the early stages of differentiation, binding of Runx2 to its genomic targets is blocked. Different mechanisms have been attributed to this block and the later release of Runx2. Bialek and colleagues [45] demonstrated that Twist proteins have an anti-osteogenic function that is mediated by the Twist box, which interacts with the Runx2 DNA-binding domain to inhibit its function in mice. As mentioned above, Runx2 is both negatively and positively regulated by Dlx3, Dlx5 and Msx2.

Many osteoblast genes in mouse cells, such as those encoding osteocalcin, osteopontin, BSP and Col1, contain functional HD regulatory elements that are regulated by Runx2 in combination with Dlx3 and Dlx5 [26]. For example, Dlx 5 binds to an HD protein binding site upstream of the two Runx2 binding sites of BSP $[46,47]$. Whereas Runx2 is constitutively bound to the BSP gene promoter in the presence or absence of Asc, Dlx 5 only binds to its HD binding site in differentiated osteoblasts that have been treated with Asc. Total Dlx5 protein levels are similar in differentiated osteoblasts and controls, and thus an increased affinity of Dlx 5 for the chromatin of the BSP gene can be attributed to Asc-induced intracellular signaling.

\section{$\beta$-Glycerophosphate}

Treatment with $\beta$-glycerophosphate can result in nonosteogenic dystrophic mineralization

$\beta$-Gly plays an important role in the osteogenic differentiation of BMSCs. Nevertheless, its use in the osteogenic differentiation of stem cells and osteoblasts has led to many false-positive results. Besides expression of some surface markers, one of the minimal prerequisites that a cell has to fulfill to be considered a mesenchymal stem cell is the capability of osteogenic, adipogenic and chondrogenic differentiation. But one has to be careful when proving this three-lineage differentiation capability. Some of the stains used to prove any of the three differentiation capabilities may lead to false results. When 
cells that are incapable of osteogenic differentiation are treated with high concentrations $(\geq 2 \mathrm{mM})$ of $\beta$-Gly they produce dystrophic mineralization or non-apatitic mineralization, which can be detected by Alizarin Red S or Von Kossa [48]. However, detection of mineralization in confluent monolayers by Alizarin Red S or Von Kossa is often the only evidence provided for osteogenic differentiation potential. If positive results for adipogenic and chondrogenic differentiation are observed for the same cells, then these cells are falsely declared to be mesenchymal stem cells. Alizarin Red S and Von Kossa cannot distinguish between different $\mathrm{Ca} / \mathrm{P}$ minerals. Lammers and colleagues [49] therefore demonstrated how a complex set of methods can be used to determine the mineral content of a sample. They used quantitative wavelength-dispersive $\mathrm{X}$-ray spectroscopy to determine whether a bone-specific $\mathrm{Ca} / \mathrm{P}$ ratio (1.67) is present in the sample, transmission electron microscopy for the characterization of hydroxylapatite-specific crystal growth, selected area electron diffraction analysis to compare diffraction patterns, and Raman spectroscopy to compare the phosphateoxygen bond of different calcium-phosphates.

One of these methods is particularly important for distinguishing between dystrophic mineralization, a product of cell death, and active mineralization of the matrix, and therefore for avoiding false-positive results for osteo-specific mineralization. With transmission electron microscopy, one can distinguish between oriented, hydroxylapatite-specific, needle-shaped crystal growth and unorganized $\mathrm{Ca} / \mathrm{P}$ depositions (such as amorphous $\mathrm{Ca} / \mathrm{P}$ ).

\section{$\beta$-Glycerophosphate serves as a phosphate source for bone mineral and induces osteogenic gene expression by extracellular related kinase phosphorylation}

Despite being the source of phosphate needed to produce the hydroxylapatite mineral $\left(\mathrm{Ca}_{10}\left(\mathrm{PO}_{4}\right)_{6}(\mathrm{OH})_{2}\right)$, recent findings have shown that inorganic phosphate (Pi) acts as an intracellular signaling molecule to regulate the expression of many osteogenic genes, including the osteopontin gene (in murine cementoblasts) [50,51] and BMP2 [52] (Figure 1). For this regulation, phosphate enters the cell and influences cell function. The activation of the ERK signaling pathway by $\mathrm{Pi}$ is biphasic and is mediated by two independent phosphorylations of ERK separated by a time interval of several hours. Only after the second phosphorylation does ERK exert its function on osteogenic gene expression. Inhibition of ERK completely inhibits osteopontin gene expression [47] and the increase in BMP2 mRNA in response to $\mathrm{Pi}$ [48]. This shows that ERK signaling is necessary for Pi-mediated increased BMP2 expression. In addition to the ERKmediated increase in BMP2 expression, Tada and colleagues [52] also demonstrated that Pi increases BMP2 expression by activation of the cyclic-AMP/protein-
kinase-A pathway. Interestingly, they also demonstrated that both pathways operate independently of each other.

\section{Conclusion}

It appears that FHL2 is a crucial factor in the osteogenic commitment of BMSCs and that the key event by which Dex induces osteogenesis is the upregulation of FHL2 expression. FHL2 induces the expression of the master osteogenic transcription factor Runx2. Furthermore, Dex leads to the upregulation of TAZ, which binds to Runx2 in the nucleus where it regulates osteoblastic differentiation by recruiting core components of the transcriptional machinery. Additionally, Dex induces osteogenic differentiation of BMSCs by increasing the expression of MKP-1 (a component of the MAPK signaling pathway), which dephosphorylates and thereby activates Runx2. The addition of Asc facilitates osteogenic differentiation by increasing the secretion of Col1, resulting in an increased binding of $\alpha_{2} \beta_{1}$ integrins to Col1. This in turn leads to the phosphorylation of ERK1/2 in the MAPK signaling pathway and subsequent translocalization of PERK1/2 to the nucleus, where it binds to Runx2 and induces gene expression of osteogenic proteins. $\beta$-Gly facilitates osteogenic differentiation by being the source of phosphate for hydroxyapatite and by the phosphorylation of ERK1/2.

\section{Abbreviations}

Asc: Ascorbic acid; BMP: Bone morphogenetic protein; BMSC: Bone marrow stromal cell; BSP: Bone sialo protein; Col1: Collagen type 1;

Dex: Dexamethasone; ECM: Extracellular matrix; ERK: Extracellular related kinase; HD: Homeodomain; MAPK: Mitogen-activated protein kinase; MKP1: MAPK phosphatase; Pi: Inorganic phosphate; SSC: Skeletal stem cell; $\beta$ Gly: $\beta$-glycerophosphate.

\section{Competing interests}

The authors declare that they have no competing interests.

\section{Acknowledgments}

This review was supported by the Deutsche Forschungsgemeinschaft (DFG) grant HA 3228/3-1 and by the 'Stiftung für Altersforschung' of the HeinrichHeine University Düsseldorf.

\section{Published: 30 September 2013}

\section{References}

1. Robey PG: Cell sources for bone regeneration: the good, the bad, and the ugly (but promising). Tissue Eng Part B Rev 2011, 17:423-430.

2. Kögler G, Sensken S, Airey JA, Trapp T, Müschen M, Feldhahn N, Liedtke S, Sorg RV, Fischer J, Rosenbaum C, Greschat S, Knipper A, Bender J, Degistirici O, Gao J, Caplan Al, Colletti EJ, Almeida-Porada G, Müller HW, Zanjani E, Wernet P: A new human somatic stem cell from placental cord blood with intrinsic pluripotent differentiation potential. J Exp Med 2004, 200:123-135.

3. Handschel J, Naujoks C, Langenbach F, Berr K, Depprich RA, Ommerborn MA, Kubler NR, Brinkmann M, Kogler G, Meyer U: Comparison of ectopic bone formation of embryonic stem cells and cord blood stem cells in vivo. Tissue Eng Part A 2010, 16:2475-2483.

4. Mackie EJ, Tatarczuch L, Mirams M: The skeleton: a multi-functional complex organ. The growth plate chondrocyte and endochondral ossification. J Endocrinol 2011, 211:109-121. 
5. Bianco P, Robey PG, Simmons PJ: Mesenchymal stem cells: revisiting history, concepts, and assays. Cell Stem Cell 2008, 2:313-319.

6. Sacchetti B, Funari A, Michienzi S, Di Cesare S, Piersanti S, Saggio I, Tagliafico E, Ferrari S, Robey PG, Riminucci M, Bianco P: Self-renewing osteoprogenitors in bone marrow sinusoids can organize a hematopoietic microenvironment. Cell 2007, 131:324-336.

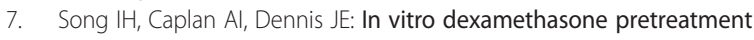
enhances bone formation of human mesenchymal stem cells in vivo. $J$ Orthop Res 2009, 27:916-921.

8. Tenenbaum HC, Heersche JN: Dexamethasone stimulates osteogenesis in chick periosteum in vitro. Endocrinology 1985, 117:2211-2217.

9. Walsh S, Jordan GR, Jefferiss C, Stewart K, Beresford JN: High concentrations of dexamethasone suppress the proliferation but not the differentiation or further maturation of human osteoblast precursors in vitro: relevance to glucocorticoid-induced osteoporosis. Rheumatology 2001, 40:74-83.

10. Seong JM, Kim BC, Park JH, Kwon IK, Mantalaris A, Hwang YS: Stem cells in bone tissue engineering. Biomed Mater 2010, 5:062001.

11. Alm JJ, Heino TJ, Hentunen TA, Väänänen HK, Aro HT: Transient 100 nM dexamethasone treatment reduces inter- and intraindividual variations in osteoblastic differentiation of bone marrow-derived human mesenchymal stem cells. Tissue Eng Part C Methods 2012, 18:658-666.

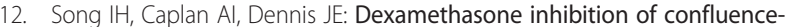
induced apoptosis in human mesenchymal stem cells. J Orthop Res 2009, 27:216-221.

13. Wang H, Pang B, Li Y, Zhu D, Pang T, Liu Y: Dexamethasone has variable effects on mesenchymal stromal cells. Cytotherapy 2012, 14:424-430.

14. Hamidouche Z, Hay E, Vaudin P, Charbord P, Schule R, Marie PJ, Fromigue $\mathrm{O}$ : FHL2 mediates dexamethasone-induced mesenchymal cell differentiation into osteoblasts by activating Wnt/beta-catenin signalingdependent Runx2 expression. Faseb J 2008, 22:3813-3822.

15. Gaur T, Lengner CJ, Hovhannisyan H, Bhat RA, Bodine PV, Komm BS, Javed A, van Wijnen AJ, Stein JL, Stein GS, Lian JB: Canonical WNT signaling promotes osteogenesis by directly stimulating Runx2 gene expression. J Biol Chem 2005, 280:33132-33140.

16. Hong D, Chen HX, Xue Y, Li DM, Wan XC, Ge R, Li JC: Osteoblastogenic effects of dexamethasone through upregulation of TAZ expression in rat mesenchymal stem cells. J Steroid Biochem Mol Biol 2009, 116:86-92.

17. Kanai F, Marignani PA, Sarbassova D, Yagi R, Hall RA, Donowitz M, Hisaminato A, Fujiwara T, Ito Y, Cantley LC, Yaffe MB: TAZ: a novel transcriptional co-activator regulated by interactions with 14-3-3 and PDZ domain proteins. EMBO J 2000, 19:6778-6791.

18. Hong JH, Hwang ES, McManus MT, Amsterdam A, Tian Y, Kalmukova R, Mueller E, Benjamin T, Spiegelman BM, Sharp PA, Hopkins N, Yaffe MB: TAZ, a transcriptional modulator of mesenchymal stem cell differentiation. Science 2005, 309:1074-1078

19. Phillips JE, Gersbach CA, Wojtowicz AM, Garcia AJ: Glucocorticoid-induced osteogenesis is negatively regulated by Runx2/Cbfa1 serine phosphorylation. J Cell Sci 2006, 119:581-591.

20. Mikami Y, Omoteyama K, Kato S, Takagi M: Inductive effects of dexamethasone on the mineralization and the osteoblastic gene expressions in mature osteoblast-like ROS17/2.8 cells. Biochem Biophys Res Commun 2007, 362:368-373.

21. Shui C, Spelsberg TC, Riggs BL, Khosla S: Changes in Runx2/Cbfa1 expression and activity during osteoblastic differentiation of human bone marrow stromal cells. J Bone Miner Res 2003, 18:213-221.

22. Franceschi RT, Xiao G: Regulation of the osteoblast-specific transcription factor, Runx2: responsiveness to multiple signal transduction pathways. $J$ Cell Biochem 2003, 88:446-454.

23. Phimphilai M, Zhao Z, Boules $H$, Roca H, Franceschi RT: BMP signaling is required for RUNX2-dependent induction of the osteoblast phenotype. $J$ Bone Miner Res 2006, 21:637-646.

24. Lee MH, Javed A, Kim HJ, Shin HI, Gutierrez S, Choi JY, Rosen V, Stein JL, van Wijnen AJ, Stein GS, Lian JB, Ryoo HM: Transient upregulation of CBFA1 in response to bone morphogenetic protein-2 and transforming growth factor beta1 in C2C12 myogenic cells coincides with suppression of the myogenic phenotype but is not sufficient for osteoblast differentiation. $J$ Cell Biochem 1999, 73:114-125.

25. Lee MH, Kim YJ, Kim HJ, Park HD, Kang AR, Kyung HM, Sung JH, Wozney JM, Ryoo HM: BMP-2-induced Runx2 expression is mediated by Dlx5, and
TGF-beta 1 opposes the BMP-2-induced osteoblast differentiation by suppression of Dlx5 expression. J Biol Chem 2003, 278:34387-34394.

26. Hassan MQ, Javed A, Morasso MI, Karlin J, Montecino M, van Wijnen AJ, Stein GS, Stein JL, Lian JB: DIx3 transcriptional regulation of osteoblast differentiation: temporal recruitment of Msx2, Dlx3, and DIx5 homeodomain proteins to chromatin of the osteocalcin gene. Mol Cell Biol 2004, 24:9248-9261.

27. Nakashima K, Zhou X, Kunkel G, Zhang Z, Deng JM, Behringer RR, de Crombrugghe $B$ : The novel zinc finger-containing transcription factor osterix is required for osteoblast differentiation and bone formation. Cell 2002, 108:17-29.

28. Sierra J, Villagra A, Paredes R, Cruzat F, Gutierrez S, Javed A, Arriagada G, Olate J, Imschenetzky M, Van Wijnen AJ, Lian JB, Stein GS, Stein JL, Montecino M: Regulation of the bone-specific osteocalcin gene by p300 requires Runx2/Cbfa1 and the vitamin D3 receptor but not p300 intrinsic histone acetyltransferase activity. Mol Cell Biol 2003, 23:3339-3351.

29. Afzal F, Pratap J, Ito K, Ito Y, Stein JL, van Wijnen AJ, Stein GS, Lian JB, Javed A: Smad function and intranuclear targeting share a Runx2 motif required for osteogenic lineage induction and BMP2 responsive transcription. J Cell Physiol 2005, 204:63-72.

30. Mehra-Chaudhary $R$, Matsui $H$, Raghow R: Msx3 protein recruits histone deacetylase to down-regulate the Msx1 promoter. Biochem J 2001 353:13-22.

31. Zhou YL, Lei Y, Snead ML: Functional antagonism between Msx2 and CCAAT/enhancer-binding protein alpha in regulating the mouse amelogenin gene expression is mediated by protein-protein interaction. J Biol Chem 2000, 275:29066-29075.

32. Vater $C$, Kasten $P$, Stiehler M: Culture media for the differentiation of mesenchymal stromal cells. Acta Biomater 2011, 7:463-477.

33. Franceschi RT, lyer BS: Relationship between collagen synthesis and expression of the osteoblast phenotype in MC3T3-E1 cells. J Bone Miner Res 1992, 7:235-246.

34. Jaiswal N, Haynesworth SE, Caplan Al, Bruder SP: Osteogenic differentiation of purified, culture-expanded human mesenchymal stem cells in vitro. J Cell Biochem 1997, 64:295-312.

35. Xiao G, Gopalakrishnan R, Jiang D, Reith E, Benson MD, Franceschi RT: Bone morphogenetic proteins, extracellular matrix, and mitogen-activated protein kinase signaling pathways are required for osteoblast-specific gene expression and differentiation in MC3T3-E1 cells. J Bone Miner Res 2002, 17:101-110.

36. Xiao G, Wang D, Benson MD, Karsenty G, Franceschi RT: Role of the alpha2integrin in osteoblast-specific gene expression and activation of the Osf2 transcription factor. J Biol Chem 1998, 273:32988-32994.

37. Franceschi RT, lyer BS, Cui Y: Effects of ascorbic acid on collagen matrix formation and osteoblast differentiation in murine MC3T3-E1 cells. J Bone Miner Res 1994, 9:843-854

38. Kundu AK, Khatiwala CB, Putnam AJ: Extracellular matrix remodeling, integrin expression, and downstream signaling pathways influence the osteogenic differentiation of mesenchymal stem cells on poly(lactide-coglycolide) substrates. Tissue Eng Part A 2009, 15:273-283.

39. Langenbach F, Naujoks C, Kersten-Thiele PV, Berr K, Depprich RA, Kubler NR, Kogler G, Handschel J: Osteogenic differentiation influences stem cell migration out of scaffold-free microspheres. Tissue Eng Part A 2010, 16:759-766.

40. Langenbach F, Berr K, Naujoks C, Hassel A, Hentschel M, Depprich R, Kubler NR, Meyer U, Wiesmann HP, Kogler G, Handschel J: Generation and differentiation of microtissues from multipotent precursor cells for use in tissue engineering. Nat Protoc 2011, 6:1726-1735.

41. Langenbach F, Naujoks C, Smeets R, Berr K, Depprich R, Kubler N, Handschel J: Scaffold-free microtissues: differences from monolayer cultures and their potential in bone tissue engineering. Clin Oral Investig 2013, 17:9-17.

42. Li Y, Ge C, Franceschi RT: Differentiation-dependent association of phosphorylated extracellular signal-regulated kinase with the chromatin of osteoblast-related genes. J Bone Miner Res 2010, 25:154-163.

43. Pokholok DK, Zeitlinger J, Hannett NM, Reynolds DB, Young RA: Activated signal transduction kinases frequently occupy target genes. Science 2006, 313:533-536.

44. Frendo JL, Xiao G, Fuchs S, Franceschi RT, Karsenty G, Ducy P: Functional hierarchy between two OSE2 elements in the control of osteocalcin gene expression in vivo. J Biol Chem 1998, 273:30509-30516. 
45. Bialek P, Kern B, Yang X, Schrock M, Sosic D, Hong N, Wu H, Yu K, Ornitz DM, Olson EN, Justice MJ, Karsenty G: A twist code determines the onset of osteoblast differentiation. Dev Cell 2004, 6:423-435.

46. Roca H, Phimphilai M, Gopalakrishnan R, Xiao G, Franceschi RT: Cooperative interactions between RUNX2 and homeodomain protein-binding sites are critical for the osteoblast-specific expression of the bone sialoprotein gene. J Biol Chem 2005, 280:30845-30855.

47. Franceschi RT, Ge C, Xiao G, Roca H, Jiang D: Transcriptional regulation of osteoblasts. Cells Tissues Organs 2009, 189:144-152.

48. Bonewald LF, Harris SE, Rosser J, Dallas MR, Dallas SL, Camacho NP, Boyan B, Boskey A: Von Kossa staining alone is not sufficient to confirm that mineralization in vitro represents bone formation. Calcif Tissue Int 2003, 72:537-547.

49. Lammers L, Naujoks C, Berr K, Depprich R, Kübler N, Meyer U, Langenbach F, Lüttenberg B, Kögler G, Wiesmann HP, Handschel J: Impact of DAG stimulation on mineral synthesis, mineral structure and osteogenic differentiation of human cord blood stem cells. Stem Cell Res 2012, 8:193-205.

50. Foster BL, Nociti FH Jr, Swanson EC, Matsa-Dunn D, Berry JE, Cupp CJ, Zhang P, Somerman MJ: Regulation of cementoblast gene expression by inorganic phosphate in vitro. Calcified Tissue Int 2006, 78:103-112.

51. Fatherazi S, Matsa-Dunn D, Foster BL, Rutherford RB, Somerman MJ, Presland RB: Phosphate regulates osteopontin gene transcription. J Dent Res 2009, 88:39-44.

52. Tada H, Nemoto E, Foster BL, Somerman MJ, Shimauchi H: Phosphate increases bone morphogenetic protein-2 expression through cAMPdependent protein kinase and ERK1/2 pathways in human dental pulp cells. Bone 2011, 48:1409-1416.

doi:10.1186/scrt328

Cite this article as: Langenbach and Handschel: Effects of dexamethasone, ascorbic acid and $\beta$-glycerophosphate on the osteogenic differentiation of stem cells in vitro. Stem Cell Research \& Therapy 2013 4:117.

\section{Submit your next manuscript to BioMed Central and take full advantage of:}

- Convenient online submission

- Thorough peer review

- No space constraints or color figure charges

- Immediate publication on acceptance

- Inclusion in PubMed, CAS, Scopus and Google Scholar

- Research which is freely available for redistribution 